\title{
Research on Conceptual Frame and Implementation Issues of Internationalization of Engineering Course in Chinese Universities
}

\author{
Si-Da Zhou, Li Liu, Zheng-Ping Wang, and Yuanyuan He
}

\begin{abstract}
This paper focuses on the internationalization of courses in the background of the whole internationalization of higher education. In this paper, the comparison of internationalization of higher education between the developed countries and China is briefly conducted, which figures out the opportunities and challenges of the internationalization of higher education. The literature of internationalization of engineering education is reviewed as well as the motivation of this research is introduced. The conceptual frame and implementation issues of internationalization of engineering course in Chinese universities are presented respectively. The proposed frame in this paper may support the practices of internationalization of engineering education at the institutional level.
\end{abstract}

Index Terms-Conceptual frame, engineering course, implementation, internationalization.

\section{INTRODUCTION}

Generally, internationalization is the process of planning and implementing products and services so that they can easily be adapted to specific local languages and cultures [1]. The international activities of universities dramatically expanded in volume, scope, and complexity during the past two decades [2]. These activities includes the traditional study-abroad programs, allowing students to learn about other cultures, providing access to higher education in countries where local institutions cannot meet the demand as well as other activities promote the international perspectives and skills of students, enhance foreign language abilities, and etc.

Before discussing the internationalization of higher education, it is necessary to figure out a important definition to clarify the focus of this paper. Internationalization is often confused with globalization in many situations. Altbach [2] presented that "Globalization and internationalization are related but not the same thing. Globalization is the context of economic and academic trends that are part of the reality of the $21^{\text {st }}$ century. Internationalization includes the policies and practices undertaken by academic systems and institutions and even individuals - to cope with the global academic environment. The motivations for internationalization include

Manuscript received July 30, 2014; revised November 19, 2014. This work was supported by the Academic Degrees and Graduate Education Development Program of Beijing Institute of Technology Grant 2013Y08B03-14 and "Top-quality courses" Program for Graduate Students of Beijing Institute of Technology Grant YJPK2014-A01.

The authors are with School of Aerospace Engineering in Beijing Institute of Technology, Beijing, 100081, China (e-mail: zhousida@bit.edu.cn, liuli@bit.edu.cn, appleyuanyuan@bit.edu.cn). commercial advantage, knowledge and language acquisition, enhancing the curriculum with international content, and many others."

In our research, the word "internationalization" is more suitable than "globalization", in which we discuss something about practices in higher education of engineering, especially the engineering courses. In this paper, we focus on the internationalization of engineering courses in the background of the whole internationalization of higher education.

\section{COMPARISON OF INTERNATIONALIZATION OF HIGHER EDUCATION BETWEEN DEVELOPED COUNTRIES AND CHINA}

In western developed countries, including United States, United Kingdom, Australia and etc., the universities even the whole social community have amount of experiences on the internationalization of high education. Table I shows the statistic data of the number of international students in United States.

TABLE I: STATISTIC DATA OF INTERNATIONAL STUDENTS IN UNITED STATES IN 2012 (TOP 10) [3]

\begin{tabular}{lcccc}
\hline \hline Top 10 Places of Origin & $\begin{array}{c}\text { Total } \\
\text { Students }\end{array}$ & $\begin{array}{c}\text { Undergraduate } \\
\text { Students }\end{array}$ & $\begin{array}{c}\text { Graduate } \\
\text { Students }\end{array}$ \\
\hline 1 & China & 194,029 & 74,516 & 88,429 \\
2 & India & 100,270 & 13,059 & 59,014 \\
3 & South Korea & 72,295 & 38,232 & 21,260 \\
4 & Saudi Arabia & 34,139 & 14,344 & 6,133 \\
5 & Canada & 26,821 & 12,866 & 11,190 \\
6 & Taiwan & 23,250 & 6,000 & 12,007 \\
7 & Japan & 19,966 & 9,359 & 4,403 \\
8 & Vietnam & 15,572 & 11,244 & 2,649 \\
9 & Mexico & 13,893 & 7,564 & 4,188 \\
10 & Turkey & 11,973 & 3,495 & 6,198 \\
& others & 252,287 & 118,663 & 84,959 \\
& Total & 764,495 & 309,342 & 300,430 \\
\hline \hline
\end{tabular}

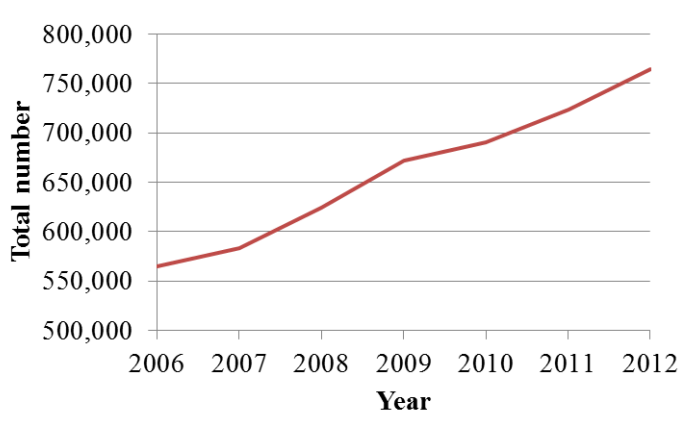

Fig. 1. Total number of the enrollment international students in United States from 2006-2012. 
As shown in Table I, the total enrollment international students in United States in 2012 have been over 760,000 and the total number of the enrollment international students in United States from 2006 to 2012 is gradually increasing as shown in Fig. 1.

Other English-speaking nations, such as United Kingdom, Australia and Canada, also have made the great achievement in the internationalization of higher education, including engineering, social science, finance, management and etc. For instance, there are 425,260 international students (non-EU) studying UK at 2012 and Table II shows the proportion of the international students to the total students in higher education organizations.

TABLE II: INTERNATIONAL STUDENTS NUMBERS BY UK NATION AND ENGLISH REGIONS 2012-2013 [4]

\begin{tabular}{ccc}
\hline \hline State & $\begin{array}{c}\text { Total international } \\
\text { students }\end{array}$ & $\begin{array}{c}\text { \% of student population } \\
\text { who are international }\end{array}$ \\
\hline England & 347,555 & $18 \%$ \\
Scotland & 46,945 & $22 \%$ \\
Wales & 24,420 & $19 \%$ \\
Northern Ireland & 6,340 & $12 \%$ \\
UK & 425,260 & $18 \%$ \\
\hline \hline
\end{tabular}

As shown in Table II, over $18 \%$ students are international in UK, this proportion seems much higher than any other countries, including United States.

The internationalization of higher education in these developed countries above does not only contribute their resources of higher education to the international students or other nations but also benefit from the internationalization of higher education itself. For instance, the international students contribute 12 billion to the United State annually, the large majority of graduates from China and India do not return home and they greatly benefit U.S. universities and the economy, the graduates of the international students greatly promote the technology and science development in these developed countries, etc.

Undoubtedly, China is the biggest developing country all over the world, which has the most population and the most number of the students in higher education. Furthermore, more than 490,000 Chinese students are enrolled by the higher education organizations and over 1,270,000 Chinese students are studying aboard. In the past three decades, more than two million Chinese people studied aboard and they made the great achievement to the world's economy including the China itself and the countries where the students studied.

China has been achieved an impressive rate of development of its economy and is increasing in its regional/global economic and political influence. With the Chinese government spending over US\$250 billion a year on education, it would not be surprising to see some Chinese universities begin to challenge the best of the West over the next few decades. Thanks to their lower fees as well as grants and scholarships from the Chinese government, many of these colleges' international students are from developing nations. Upon visiting six African nations on his first international trip as China's president, Xi Jinping announced 18,000 new scholarships for African students to study in Chinese universities over the next three years. Many of the recipients will return home with honed skills and fresh ideas on how to jumpstart their countries' economies. [5]

Actually, the national development strategy and the attraction on the economy and cultures promote the internationalization of higher education in China. Although the number of the international students in Chinese universities is much smaller than that in United States, UK and other developed countries even much smaller than that of Chinese students studied abroad, the number of the international students in Chinese universities is rapidly increasing as shown in Fig. 2.

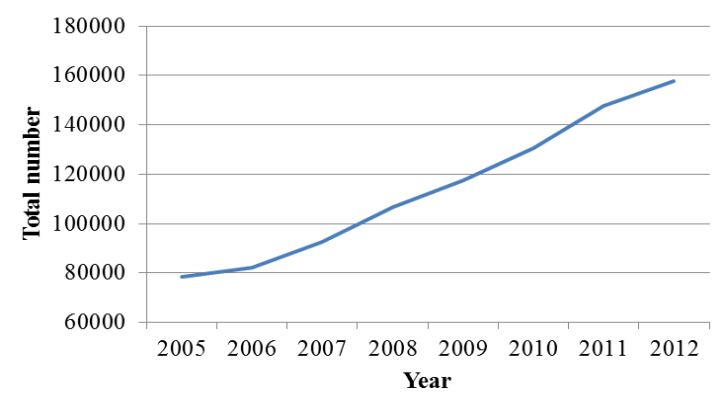

Fig. 2. Total number of the enrollment international students in China from 2005-2012.

Under promoting from the national strategy and with the increment of attraction on the economy and cultures, more and more foreign students may receive the higher education in China. It results in newer and bigger challenges, while it brings more opportunities to this biggest developing country.

\section{REVIEW OF LITERATURE AND PURPOSE OF THIS RESEARCH}

Internationalization of higher education is not only an opportunity on the economic booming and cultural transmission but also big challenges on the language problem, cultural conflict, technology protection and etc.

It is not possible to solve all problems in a single research. This paper focuses on engineering course in the internationalization circumstance. In one hand, the course is the fundamental element in the whole loop of higher education. How to make the course international is a directly and simple way to promote the higher education to be international. In the other hand, engineering, including the mechanical engineering, aerospace engineering, mechatronic engineering, electrical engineering and etc., is the basic support to the manufacture industry, which is important for developing countries, such as China and India.

In this section, the literature of relevant researches on the internationalization of engineering education and the purpose of this research are presented and discussed.

\section{A. Review of Literature}

There are many researchers and teachers studied the problems of the internationalization of higher education, which consist of many aspects, including the policy, faculty, program, assessment system, relationship with the globalized economy and etc. Juknyte-Petreikiene [6] discussed some important parameters that influence the internationalization of higher education at the institutional level and the structures of higher school internationalization, and presented the quality 
assessment. Bettencourt [7] analyzed the curriculum under the situation of foreign language education. Gopal [8] illustrated a new view point of internationalization, preparing faculty to teach cross-culturally, which emphases the role of the faculty in the internationalization of higher education. Beck [9] discussed some reproductions and the resistance in the internationalization of higher education. In this work, some key definitions in internationalization, globalization and higher education were discussed substantially. Cho and Palmer [10] investigated the Stakeholders' perceptions of South Korea's higher education internationalization policy, in which the history of Korea's policy of the internationalization of higher education was reviewed and some specific aspects of the policy were analyzed. Vajargah and Khoshnoodifar [11] presented a distance-education based strategy for internationalization of the curriculum in higher education in Iran. Altbach [12] discussed the Chinese higher education under the background of Chinese new economic and educational policy and trend.

Engineering is different from the art or science, which means more practices. Therefore, the engineering education is naturally different from the art or science education, especially for the students in higher education, including the undergraduate and graduate students.

In the past decade, many education researchers and teachers or professors in engineering teaching presented a lot of research papers and reports on the internationalization of engineering education. Pursula et al. [13] took the vehicle development as an example and presented the concept of virtual university, which promotes the development, cooperation and internationalization in teaching and learning. This work is a great example for engineering education, because practical example plays an important role in engineering education. Wu et al. [14] studied the operational research education in industry engineering subject, which emphases on the more and more complicated manufacture process and investigated the industry engineering problems and the operational research methods. Cox et al. [15] discussed some interesting problems, the leadership, policy and change course for science, technology, engineering and mathematics graduate students. Popov [16] presented a special point of view, the teachers' and students' experiences of simultaneous teaching. In this work, the teachers' and students' experiences were focused when an international distance program was implemented. Tossavainen [17] investigated the institutional-level internationalization strategy in engineering and presented the detail strategy of internationalization in engineering in Helsinki polytechnic Stadia, Finland. Guatelli et al. [18] presented a combinative approach of research and teaching, which gave an example of radiation physics. Chung [19] analyzed the engineering curriculum under the background of internationalization. In this work, the changing concepts of core competence, the changing expectations of engineering graduates, the green engineering principles and etc. were discussed. Kushnarenko and Cojocari [20] introduced the realities and perspectives of the internationalization of higher education in post-soviet small states, such as Moldova. The engineering education was emphased in this work. Fagette et al. [21] discussed the mechanical engineering general education courses in the internationalization background. Generally, the research on the international of engineering education is increasing in recent years and more aspects of the internationalization of engineering education are focused.

\section{B. Purpose of this Research}

Internationalization of engineering education consists of many aspects, including the curriculum, faculty, teacher, policy and etc. The course is one of the most important elements in the higher engineering education. At the institutional level, for example, in Beijing Institute of Technology, the authors' university, the course is the most directly aspect in the internationalization of engineering education. The purpose of this paper is to partially answer two questions: the conceptual frame of the internationalization of engineering course and the implementation issues on a graduate course, structural dynamics in aerospace engineering.

\section{DESIGN OF THE CONCEPTUAL FRAME}

A conceptual frame of internationalization of engineering course is presented in this section, which is named 12345 Frame for short. The details about the frame will be presented as follows.

\section{A. Overall Design of the Conceptual Frame}

The overall diagram of the conceptual frame of internationalization of engineering course is shown in Fig. 3.

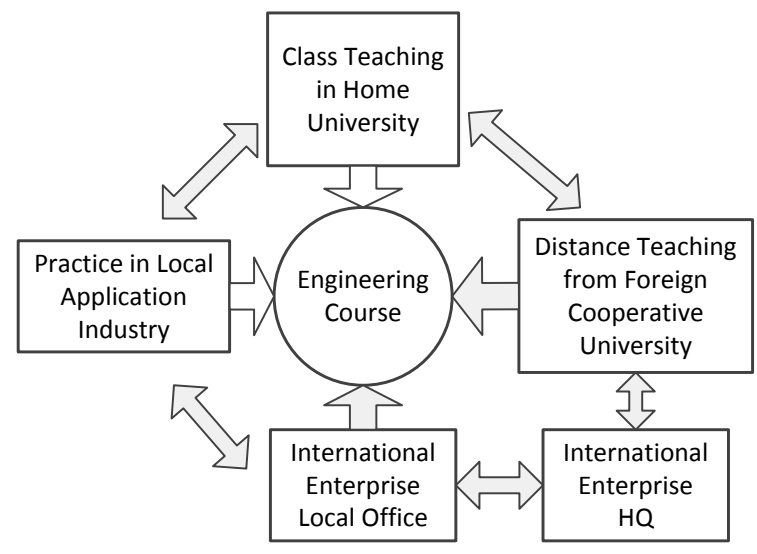

Fig. 3. Overall diagram of the conceptual frame.

As shown in Fig. 3, the engineering course is the core in the conceptual frame. This frame consists of one main body, two excitations, three teaching missions, four relations and five service blocks, which is named 12345 Frame for short.

\section{B. One Main Body}

In this conceptual frame, the main body is the students intended this course.

\section{Two Excitations}

The learning motivation of students is very important, which determine the results the teaching and learning of this course. Therefore, the enough excitations are necessary. For students, scholarship and job hunting are two possible excitations to promote their learning efficiently. In one hand, the scholarship can be provided by the university or the industry, which is a kind of substantial stimulation for 
students. In the other hand, in this frame, the international companies and local industry involve in the course, so it supplies a good opportunity for students to contact with these companies while the companies are also familiar with the students attended this course, which leads to the win-win results.

Furthermore, to involve in the international engineering course may help the enterprises to spread themselves, which is also a excitation for the industry.

\section{Three Teaching Missions}

In this frame, there are three main teaching missions: 1) theoretical teaching in the home university (Chinese university) and distance teaching from the foreign universities 2) practice teaching in the local industry and 3) practice teaching in the foreign cooperative universities in the oversea branch of international enterprises. Practice teaching in the local industry is common approach in the available engineering education system in China. The university supplies the practice opportunities of cooperative industrial organizations to the students. Furthermore, practice teaching in the foreign cooperative universities in the oversea branch of international enterprises is becoming possible recently in China.

\section{E. Four Relations}

In this frame, there are four main relations: 1) the relation between the home university (Chinese university) and the foreign universities, 2) the relation between the home university (Chinese university) and the international enterprises, 3) the relation between the home university (Chinese university) and the local industry and 4) the relation between the international enterprises and the local industry.

The outstanding universities in China, such as the universities in 211 Plan or 985 Program, commonly cooperate with the famous foreign universities, which is important resource for building the first relation. To spread their products or services in China, the international enterprises always hold some free courses or short-term training, so the relation between the home university and the international enterprises is also win-win. Normally, the alumni are normally the bridges to build the relations between the university and the local industry. Actually, from the past experiences, each outstanding university in China, especially the university majored in engineering, has a number of local industrial companies to supply the practical chances for its undergraduate or graduate students. The fourth relation, the relation between the international enterprises and the local industry is not an indispensable rather than optional. This relation does not explicitly to support the course, but it is helpful to excite both of them, because the international enterprises need to market their services or products to the local industrial companies and vice versa. Building this relation is useful for the course implicitly.

\section{F. Five Service Blocks}

As shown in Fig.3, there are five rectangles, which indicate the five service blocks in the proposed conceptual frame: the home university, the foreign cooperative universities, the local industry, international enterprises' local office and oversea branches (including their headquarters). The home university plays the main role, which organizes the internationalization of the engineering course and the class teaching and builds the four relations. The roles of other four blocks have been stated in the "Three Teaching Missions" and "Four Relations".

\section{G. Discussion}

The proposed conceptual frame of the internationalization of engineering does not only include the five service blocks as shown as the five rectangles in Fig. 3 but also is a completely organic ecosystem: the excitations drive this course forward, the three teaching missions are the directly goals and the four relations are the arteries to connect all the organs for nourishing the whole body.

\section{DISCUSSION OF THE IMPLEMENTATION ISSUES: AN EXAMPLE STUDY}

In this section, an example in authors' home university about the conceptual frame of the internationalization of engineering course is presented as well as some implementation issues.

\section{A. Overall Design of Internationalization of Course of Structural Dynamics in Beijing Institute of Technology}

As shown in Fig. 4, the design of internationalization of course of structural dynamics in Beijing Institute of Technology is a realization for the conceptual frame as shown in Fig. 3.

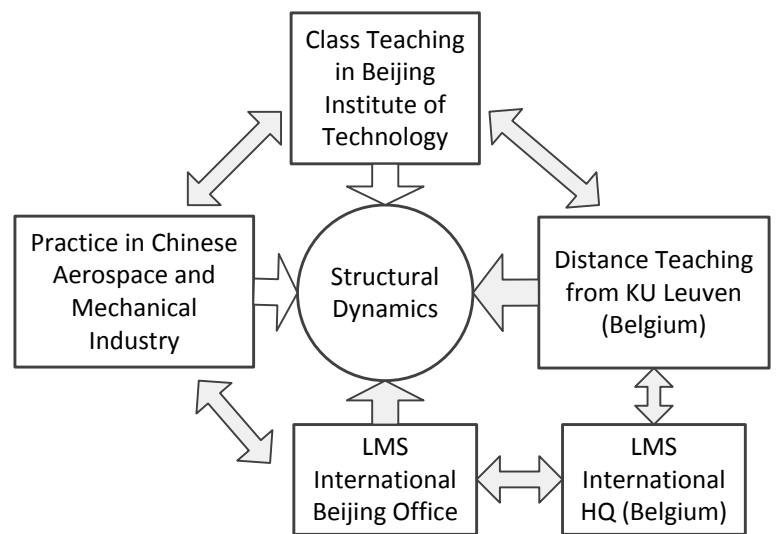

Fig. 4. Overall design of internationalization of course of structural dynamics in Beijing institute of technology.

The course is structural dynamics in aerospace engineering; the home university is authors' university, Beijing Institute of Technology; the foreign cooperative university is KU Leuven (the university of Leuven, Belgium), which a famous university in Europe and its noise and vibration research is at the top in structural dynamics research community; the international enterprise is the LMS international corporation and is a spin-off from the $\mathrm{KU}$ Leuven; the aerospace companies, such as CASC, could supply the practical opportunities to the students. In this realization, the relation between Beijing Institute of Technology and KU Leuven is very important. The authors' research group and noise and vibration group in KU Leuven has built a good cooperative relationship. A PhD student from authors' research group had finished his doctoral research in noise and vibration group in $\mathrm{KU}$ Leuven and another is preparing to start the doctoral 
research in Leuven and the professor from KU Leuven had given the lectures to Chinese student in Beijing Institute of Technology for three years.

\section{B. Language for the Course}

The two languages are used in this course, a foreign language and the native language rather than not two foreign languages. Currently, English is very popular in China as well as many other countries. The language is a tool to conduct the class both teachers and students must be familiar with the language allowing both teachers and students to communicate freely and the subject knowledge to be transmitted without obstacle. The bilingual approach is helpful for students to understand the knowledge and communicate with foreign professors as well as it is useful when students find jobs in native or oversea markets.

\section{Distance Learning}

The distance education is a process to create and provide access to learning when the source of information and the learners are separated by time and distance and it provides an educational experience of equal qualitative value for the learners to best suit their needs outside the classroom [11]. In our case, the distance learning means that the teaching materials including the demonstration and instrument in $\mathrm{KU}$ Leuven can be shared by using the distance video and the students can learn after the class. The authors' group and the group in KU Leuven will make a number a visual teaching material for the students from China and Belgium both, which are available on website.

\section{Practical Projects at the Course Level}

In our experience, the practical projects can encourage students to find, analyze and synthesize new knowledge themselves, which is the actually essential part of engineering education. In this mode, the class is divided into several groups. The teacher should balance each group at an equivalent level of language and knowledge of students. Then each group chooses a topic listed by the teacher, searches for relevant materials, organizes the materials, prepares and finally makes a presentation. Additionally, when they do the teamwork different members in each group may have different tasks. Students experience how to cooperate with others and this kind of group spirit will benefit them greatly in their future careers. The topics of the projects are from the past experience of authors' group and the group in $\mathrm{KU}$ Leuven or from the cooperative companies. The students can implement the projects in the sites of a real engineering location, which are managed by the cooperative companies, or in the laboratory of Beijing Institute of Technology.

\section{E. Financial Support}

Engineering practices have to spend a number of financial resources. The cost of the course consists of the projects, traveling cost of foreign professors and scholarships. The cost of the practical projects will be covered by Beijing Institute Technology and the cooperative companies; the traveling cost of foreign professors can be covered by the foundation of the international cooperation from the Chinese government or the universities; the scholarship for the students in this course is from Graduate School of Beijing Institute of Technology and the social donations, such the cooperative companies and alumni.

\section{CONCLUSION}

This paper investigates the internationalization of engineering courses in case of the whole internationalization of higher education. The internationalization of higher education between developed countries and China is briefly compared. The strong need of the internationalization of higher education in China has been analyzed. The literature of internationalization of engineering education is reviewed which also reveals the motivation of this work. The conceptual frame internationalization of engineering course in Chinese universities are presented, which is a 12345 Frame including one main body, two excitations, three teaching missions, four relations and five service blocks. The frame is an organic ecosystem including the excitations to drive, relations to connect and etc. Finally, an example case study demonstrates the proposed frame and several key implementation issues are presented.

This research focuses on the needs of internationalization of Beijing Institute of Technology and requirement of top-quality education. The frame of the internationalization of engineering course is not only useful for the course in the example of this paper but also can be a reference for other engineering courses in Beijing Institute of Technology or other universities majored in engineering.

\section{REFERENCES}

[1] M. Rouse. (2011). What is the internationalization? [Online]. Available:

http://whatis.techtarget.com/definition/internationalization-I18N

[2] P. G. Altbach and J. Knight, "The internationalization of higher education: Motivations and realities," Journal of Studies in International Education, vol. 11, pp. 290-305, 2007.

[3] International Students in the United States, Institute of International Education, Inc., 2012.

[4] (2014). International student statistics: UK higher education. [Online]. Available:

http://www.ukcisa.org.uk/Info-for-universities-colleges--schools/Polic y-research--statistics/Research--statistics/International-students-in-U K-HE/

[5] R. Ghiasy, S. Mothe, and F. Pontemayor. (2013). China's Developing World Edge. [Online]. Available: http://thediplomat.com/2013/09/chinas-developing-world-edge/

[6] I. Juknyte-Petreikiene, "Parameters of higher school internationalization and quality assessment," Quality of Higher Education, vol. 3, pp. 92-122, 2006.

[7] M. Bettencourt, "Languages across the curriculum: A response to internationalization in foreign language education," Multicultural Education, vol. 19, pp. 55-58, 2011.

[8] A. Gopal, "Internationalization of higher education: Preparing faculty to teach cross-culturally," International Journal of Teaching and Learning in Higher Education, vol. 23, pp. 373-381, 2011.

[9] K. Beck, "Globalizations: Reproduction and resistance in the internationalization of higher education," Canadian Journal of Education, vol. 35, pp. 133-148, 2012.

[10] Y. H. Cho and J. D. Palmer, "'Stakeholders' views of South Korea's higher education internationalization policy," Higher Education: The International Journal of Higher Education and Educational Planning, vol. 65, pp. 291-308, 2013.

[11] K. F. Vajargah and M. Khoshnoodifar, "Toward a distance education based strategy for internationalization of the curriculum in higher education of Iran," Turkish Online Journal of Educational Technology - TOJET, vol. 12, pp. 147-160, 2013.

[12] P. Altbach, Chinese "Higher education in an open-door era," The International Imperative in Higher Education, Sense Publishers, 2013, pp. $157-161$ 
[13] M. Pursula, M. Warsta, and I. Laaksonen, "Virtual University-A vehicle for development, cooperation and internationalisation in teaching and learning," European Journal of Engineering Education, vol. 30, pp. 439-446, 2005.

[14] Y.-H. Wu, F.-M. Wang and G. Du, "Research and exploration for operational research education in industry and engineering subject," US-China Education Review, vol. 4, pp. 25-29.

[15] M. F. Cox, C. A. Berry, and K. A. Smith, "Development of a leadership, policy, and change course for science, technology, engineering, and mathematics graduate students," Journal of STEM Education: Innovations and Research, vol. 10, pp. 9-16, 2009.

[16] O. Popov, "Teachers' and students' experiences of simultaneous teaching in an international distance and on-campus master's programme in engineering," International Review of Research in Open and Distance Learning, vol. 10, 2009.

[17] P. J. Tossavainen, "Institutionalising strategies in engineering education," European Journal of Engineering Education, vol. 34, pp. $527-543,2009$.

[18] S. Guatelli, C. Layton, D. Cutajar, and A. B. Rosenfeld, "The teaching/research nexus and internationalisation: An action research project in radiation physics," Journal of University Teaching and Learning Practice, vol. 7, 2010.

[19] C. Chung, "Changing engineering curriculum in the globalizing world," New Horizons in Education, vol. 59, pp. 59-70, 2011

[20] V. Kushnarenko and L. Cojocari, "Internationalization of higher education in post-soviet small states: Realities and perspectives of moldova," Current Issues in Comparative Education, vol. 15, pp. 132-144.

[21] P. Fagette, S.-J. Chen, G. R. Baran, S. P. Samuel, and M. F. Kiani, "Engineering a general education program: Designing mechanical engineering general education courses," Innovative Higher Education, vol. 38, pp. 117-128, 2013.

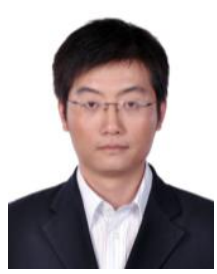

Si-Da Zhou received his doctoral degree in flight vehicle design from School of Aerospace Engineering, Beijing Institute of Technology in 2012 and bachelor degree in flight vehicle design and engineering from School of Aerospace Engineering, Beijing Institute of Technology in 2007. He is a lecturer of School of Aerospace Engineering, Beijing Institute of Technology. His research interests include structural dynamics in aerospace engineering, modal analysis theory and testing, time-varying structural system modelling and its modal parameter estimation.

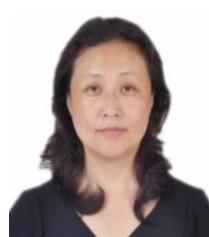

Li Liu received her doctoral degree in airplane design from the Department of Airplane Design Engineering, Beihang University in 1991. She is a professor of School of Aerospace Engineering, Beijing Institute of Technology. Her research interests include flight vehicle design, structural dynamics in aerospace engineering and etc.

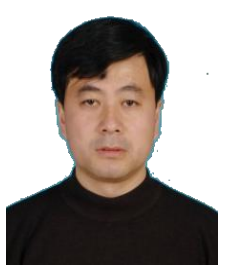

Zheng-Ping Wang received his doctoral degree in flight vehicle design from School of Aerospace Engineering, Beijing Institute of Technology in 2013. $\mathrm{He}$ is an experimentalist in School of Aerospace Engineering, Beijing Institute of Technology. His research interests include structural dynamics in aerospace engineering, testing technology and etc.

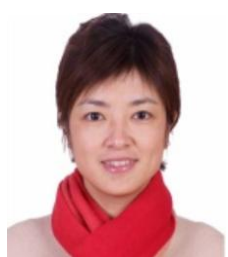

Yuanyuan He received her doctoral degree in flight vehicle design from School of Aerospace Engineering, Beijing Institute of Technology in 2013. She is an associate professor of School of Aerospace Engineering, Beijing Institute of Technology. Her research interests include smart structures and structural dynamics in aerospace engineering and etc. 